\title{
The effect of vitamin $D$ dose on bone mineral density: response to comment by Heaney
}

\author{
G. Grimnes
}

Received: 3 November 2011 / Accepted: 3 November 2011 / Published online: 24 November 2011

(C) International Osteoporosis Foundation and National Osteoporosis Foundation 2011

\section{Dear Editor,}

I and my co-authors acknowledge the many challenges of clinical studies of nutrients such as vitamin D [1], and appreciate that Dr Heaney [2] seems to agree with the limitations of our study as already pointed out in the discussion section of our paper [3]. Hopefully, ongoing or future studies will overcome these problems.

Conflicts of interest None.

\section{References}

1. Heaney RP (2008) Nutrition, endpoints and the problem of proof. J Nutr 138(9):1591-1595

2. Heaney RP (2011) The effect of vitamin D dose on bone mineral density. Osteoporos Int. doi:10.1007/s00198-011-1844-2

3. Grimnes G, Joakimsen R, Figenschau Y, Torjesen PA, Almås B, Jorde R (2011) The effect of high-dose vitamin D on bone mineral density and bone turnover markers in postmenopausal women with low bone mass - a randomized controlled 1-year trial. Osteoporos Int. doi:10.1007/s00198-011-1752-5, Epub ahead of print 10 September 2011

G. Grimnes $(\bowtie)$

Tromsø Endocrine Research Group,

Department of Clinical Medicine, University of Tromsø,

9037 Tromsø, Norway

e-mail: guri.grimnes@unn.no 